\title{
Effects of A 3-Month Physiotherapy Intervention in Stable Cervical Dystonia As Add-On to Botulinum Toxin Therapy
}

\section{Effekte einer dreimonatigen Physiotherapieintervention als Add- on Behandlung bei Patienten mit zervikaler Dystonie}

\author{
Authors \\ Christian Werner ${ }^{1}$, Steffen Derlien², Norman Best ${ }^{2}$, Otto Witte ${ }^{3}$, Ulrich Christian Smolenski², Albrecht Günther ${ }^{3}$
}

\author{
Affiliations \\ 1 Neurology, St Georg Klinikum Eisenach, Eisenach \\ 2 Institut für Physiotherapie, Universitätsklinikum Jena, Jena \\ 3 Department of Neurology, Jena, Universitätsklinikum \\ Jena, Thüringen, Jena
}

Key words

zervikale Dystonie, Torticollis spasmodicus

received 26.09.2018

accepted 27.09.2018

Bibliography

DOI https://doi.org/10.1055/a-0756-9954

Published online: 19.11.2018

Phys Med Rehab Kuror 2019; 29: 53-57

(C) Georg Thieme Verlag KG Stuttgart · New York

ISSN 0940-6689

Correspondence

Dr. Christian Werner

Medical Doctor

St Georg Klinikum Eisenach Neurology

Mühlhäuserstraße 94-95

99848 Eisenach

werner.ch.1987@web.de

\section{ABSTRACT}

Background Treatment of choice for cervical dystonia comprises botulinum neurotoxin therapy. Whether additional physiotherapy can achieve better results is unclear.

Objectives To show effects of physiotherapy as an add-on treatment to botulinum neurotoxin therapy.

Methods 18 patients participated in this prospective interventional study (DRKS00006562) consisting of 2, 3-month periods. In the first period, usual botulinum toxin was applied. The second period comprised an additional multimodal physiotherapy program. Outcome measures were: range of motion, SF-36, Toronto Western Spasmodic Torticollis Rating Scale (TWSTRS), surface electromyography.

Results In the comparison first phase vs. second phase patients showed significant improvements in range of motion (flexion/ extension: $16.3 \pm 25.4$; rotation: $19.1 \pm 24.6$ ), TWSTRS (severi- ty: $3.8 \pm 3.0$; disability: $1.7 \pm 2.0$; pain: $4.4 \pm 4,1$ ) and in mental health (SF-36: $5.9 \pm 7.5$ ); $\mathrm{p}<0.05$, respectively. No significant changes were seen in the lateral flexion ROM, physical health (SF-36) and the surface electromyography.

Conclusion Multimodal physiotherapy is a feasible and save additional treatment option for patients with cervical dystonia. An add-on physiotherapy program can achieve better treatment outcomes. Patients benefited especially with improved range of motion, and reduced pain and severity of symptoms.

\section{ZUSAMMENFASSUNG}

Hintergrund Therapie der Wahl bei zervikaler Dystonie ist die Behandlung mit Botulinumneurotoxin. Ob jedoch zusätzliche physiotherapeutische Maßnahmen einen Nutzen bringen, ist nach aktuellem Forschungsstand nicht eindeutig belegt.

Ziel Ziel der Studie war es, Effekte einer multimodalen Physiotherapie als Add-on Behandlung zur Botulinumneurotoxintherapie aufzuzeigen.

Methoden 18 Patienten nahmen an dieser prospektiven interventionellen Studie (DRKS00006562) teil, welche aus 2 Phasen mit jeweils 3 Monaten Dauer bestand. In der ersten Phase wurde die übliche Botulinumtoxin-Therapie durchgeführt. Die zweite Phase umfasste ein zusätzliches multimodales Physiotherapieprogramm. Outcome-Parameter waren: Range of Motion (ROM), SF-36, Toronto Western Spasmodic Torticollis Rating-Skala (TWSTRS) sowie eine Oberflächen-Elektromyografie.

Ergebnisse Im Vergleich der ersten Phase mit der zweiten Phase konnten signifikante Verbesserungen des Bewegungsumfangs (Flexion / Extension: 16,3 \pm 25,4; Rotation: $19,1 \pm$ 24,6), des TWSTRS (Schweregrad: 3,8 \pm 3), 0; Einschränkung: 1,7 \pm 2,0; Schmerz: 4,4 $\pm 4,1$ ) (Schweregrad: 3,8 $\pm 3,0$; Alltagseinschränkung: 1,7 \pm 2,0; Schmerz: $4,4 \pm 4,1)$ und der psychischen Gesundheitswahrnehmung (SF-36: 5,9 \pm 7,5) festgestellt werden $(p<0,05)$. Die Differenzen der Lateralflexion (ROM), der physischen Gesundheitswahrnehmung (SF-36) und der Oberflächen-Elektromyografie zeigten keine signifikanten Veränderungen.

Schlussfolgerung Multimodale Physiotherapie ist eine sichere zusätzliche Behandlungsoption für Patienten mit zervikaler Dystonie. Ein zusätzliches, multimodales Physiotherapie Programm kann bessere Behandlungsergebnisse gerade im Bereich Beweglichkeit, Schweregrad der Erkrankung und Schmerzen erzielen. 
Cervical dystonia (CD) most commonly occurs as primary adult onset dystonia between the ages $30-50$ years with an estimated prevalence of $16.4 / 100,000$ persons [1]. Dystonias are movement disorders with persistent involuntary contractions of striated skeletal muscles, which often lead to abnormal postures and head and neck position [2,3]. In the case of $C D$, the disorder usually affects a number of cervical muscles, especially the superior fibers of the trapezius muscle, sternocleidomastoid muscle, plus the splenius and scalenus muscles. Notably, $75 \%$ of CD-patients also suffer from pain, a symptom not present in other focal dystonias [4].

At present, only symptomatic-based treatment options are available. The treatment of choice is selective peripheral denervation of the affected muscles with local injections of botulinum neurotoxin type A (BoNT-A) [5]. Currently, the German Neurological Society guidelines do not give recommendations for applying physiotherapy (PT) treatment in patients with CD [6]. Consequently, the effects of additional physiotherapy in CD-patients have rarely been examined. De Pauw et al. recently published a systematic review of 10 case or series reports and 6 clinical trials [7]. Due to the heterogeneous nature of the trials examined such as the different physiotherapy techniques, the differing duration of interventions and varying outcome measures, it is difficult to compare study data and results. However, the authors concluded that multimodal physiotherapy concepts with a focus on active exercises in combination with BoNT-A treatment would probably have a beneficial effect on pain, on severity of the CD, and on the activities of daily living. Although, further studies with standardized outcome measures are required before any specific recommendations can be given [7].

The present study aims to evaluate an add-on multimodal physiotherapy program over a period of 12 weeks with twice-weekly interventions. The treatment techniques used in the study are established methods that can be adapted to individual complaints and deficits of the patient by any physiotherapist.

\section{Study design}

This monocentric, prospective interventional study involved an interdisciplinary collaboration between the Departments of Neurology and Physiotherapy of a large tertiary care University Hospital. Study registration took place (DRKS00006562) and Institutional Review Board approval was granted (processing number: 4122-
06/14). Study duration for each of the 18 patients amounted to 6 months and was divided into 2 phases ( $\triangleright$ Fig. $\mathbf{1}$ ).

The first phase began on the day of the BoNT-A injection and ended 3 months later (day of the second BoNT-A injection). During this time, the participants were assessed 3 times: on the first day (T0), after 6 weeks (T1) and on the last day of the first phase (T2). In the second phase, the add-on physiotherapy program was carried out. This phase also lasted 3 months beginning with the second BoNT-A treatment (T2) and ending with the third BoNT-A injection (T4). Two assessments were undertaken during this phase, at six weeks after $\mathrm{T} 2$ and at the time of the third BoNT-A injection (T3 and T4, respectively) [8].

Inclusion criteria were diagnosis of cervical dystonia, continuous treatment with BoNT-A at a 3-month interval, at least one year of continuous treatment with BoNT-A, and patient's informed consent.

Exclusion criteria were contraindications for the physiotherapy treatment (trauma, local inflammation, neoplasia) and contraindications for the BoNT-A treatment (BoNT allergy, gestation, local myositis).

Primary endpoint were changes in the range of motion of the cervical spine evaluated by the measuring system ZEBRIS [9]. The system employs a special triple marker integrated miniature ultrasonic transmitter that is fixed to the patient's head plus a sensor for measuring ultrasonic signals ( $>$ Fig. 2). This setup detects exactly the range of motion in all 3 directions of movement. Co-primary endpoint was the quality of life assessed by means of the SF-36 score, a non-specific disease measuring instrument [10]. The score is a patient report survey used to detect changes in patient's physical and mental health.

Secondary endpoint was the Toronto Western Spasmodic Rating Scale (TWSTRS) which includes severity, disability, and pain due to cervical dystonia [11]. This is the most common scale to qualify the severity of CD and it is also recommended by Albanese et al. [12] and De Pauw et al. [7] for comparing study outcomes with other trials. In addition, electrical activity from the superior fibers of the trapezius muscle and from the sternocleidomastoid muscle, 2 highly relevant muscles involved in idiopathic cervical dystonia [13], were determined by means of surface electromyography as another secondary endpoint. In this assessment, the resting muscle tone (in $\mu \mathrm{V}$ ) was analyzed by comparing tone side differences (in percent) of each of the 2 muscles $[14,15]$.

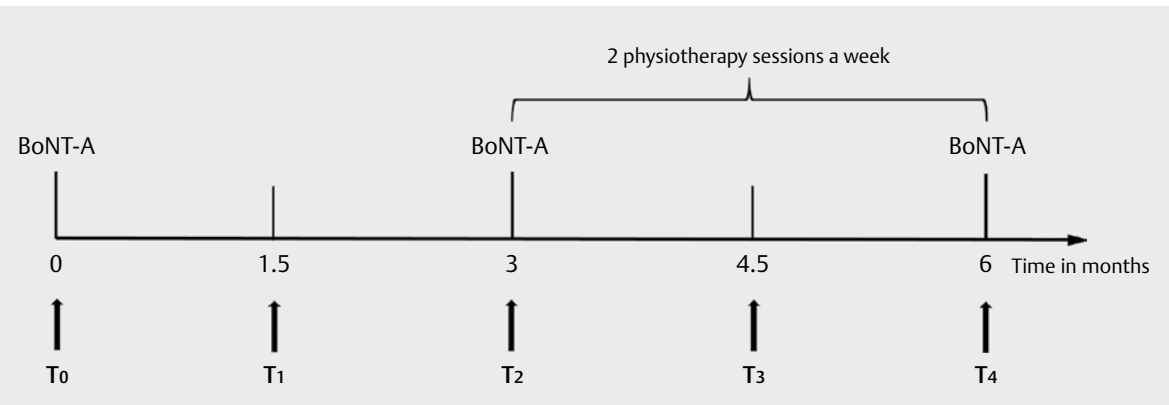

- Fig 1 Study timeline (BoNT-A: botulinum neurotoxin A injections) 


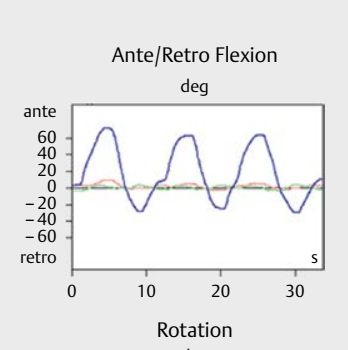

ROM measurement report from a study patient at T1
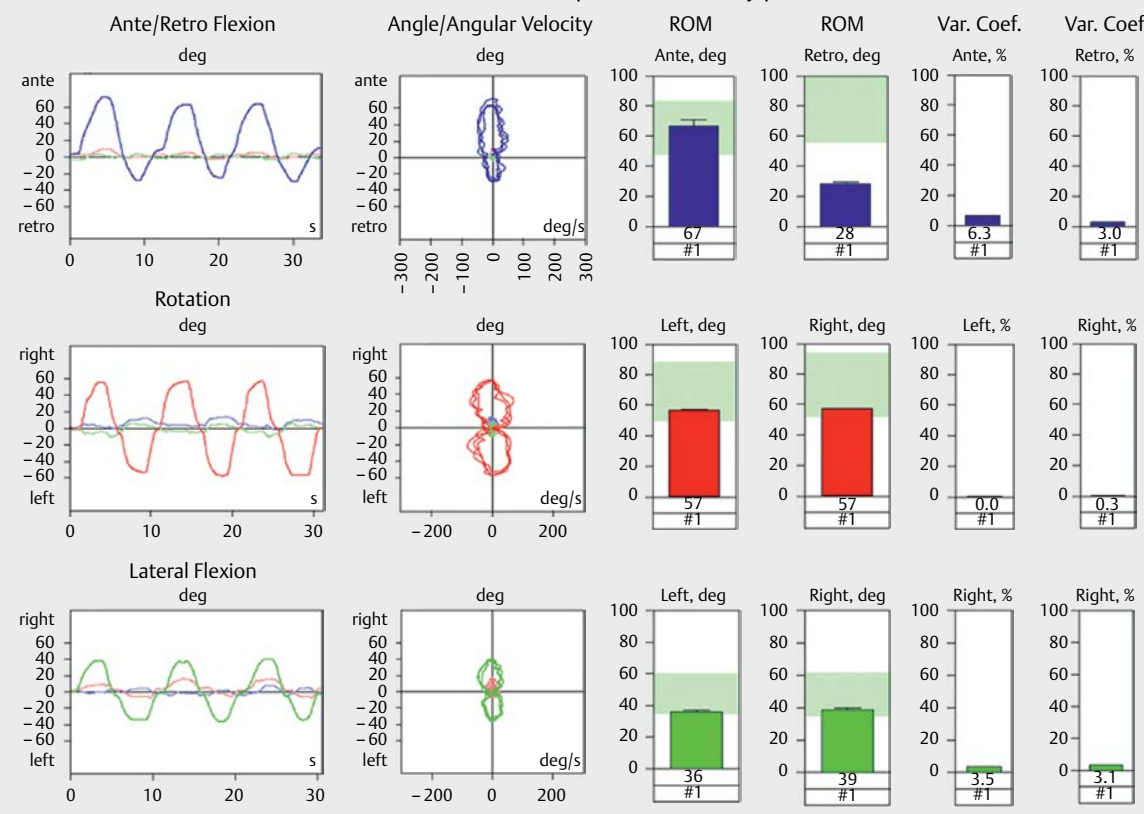

ROM measurement report from a study patient at T4
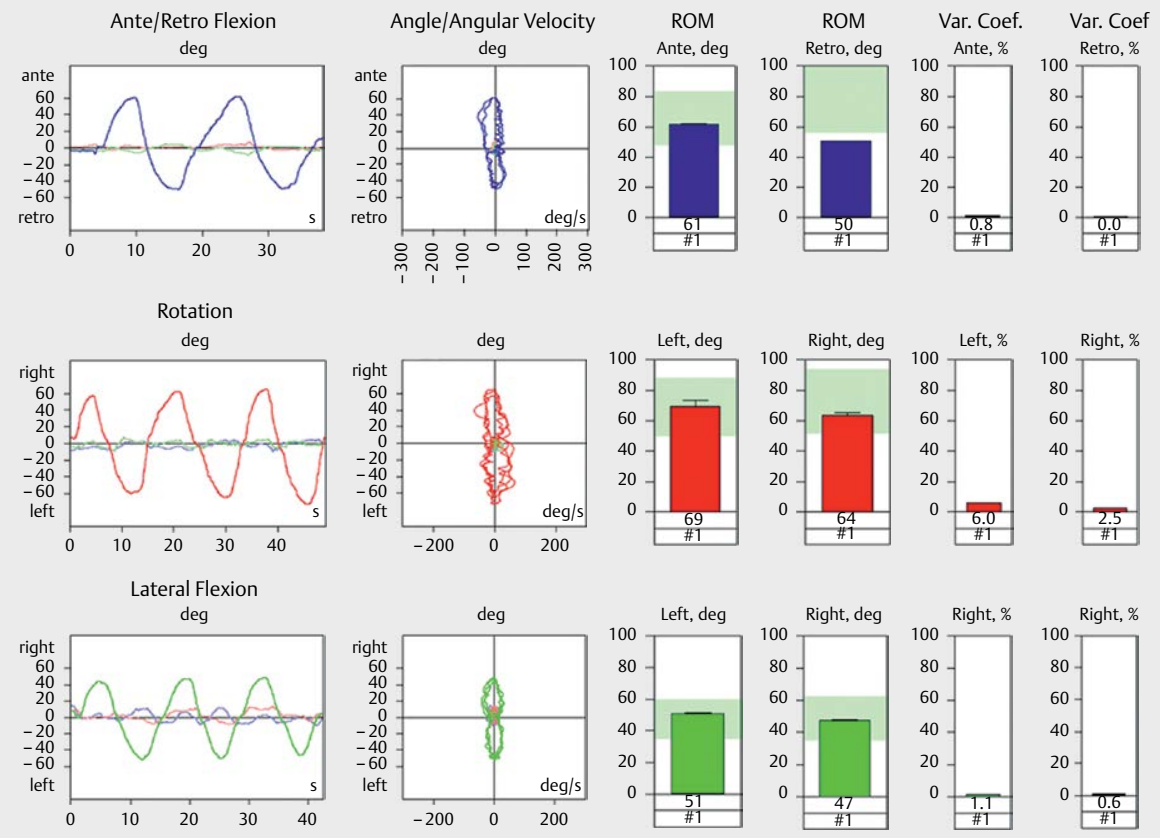

- Fig 2 Changes in ROM detected employing ultrasonic-based measurement system (Zebris, inset). ROM analysis in different planes and functions of a $C D$ patient at baseline and at the end of the intervention phase.

Physiotherapeutic interventions were undertaken during the entire second study phase. The intervention comprised 24 treatments bouts involving two 45-min sessions per week over a 12-week period. Primary physiotherapeutic aims included reduction of pathological movement patterns and tone improvement in the hyperkinetic muscles. Furthermore, the proprioception of head posture, control of head posture, the activities of daily living, pain, and the mobility of the cervical spine were therapy approaches. Transcutaneous electrical nerve stimulation (TENS electrotherapy) therapy was also applied for 15 min per session. Hence, each PT session comprised $30 \mathrm{~min}$ of active and passive exercises and $15 \mathrm{~min}$ of TENS electrotherapy.

The main physiotherapeutic techniques consisted of passive and active mobilization of the cervical spine and the shoulder girdle, 
isometric cervical spine exercises, mirror feedback exercises, perception and coordination training, as well as posture training and relaxation techniques.

\section{Statistical analysis}

Means and standard deviation were used for demographic data and baseline values. To examine differences between the 2 treatment periods, the t-test and the Wilcoxon test were applied at a significance level of $p<0.05$. SPSS 22.0 software was used for statistical analysis.

\section{Results}

18 patients were examined with a mean age of 63.5 ( \pm 13.6$)$ and a gender distribution of $3 / 15$ (male/female). The mean disease duration was 7.5 ( \pm 6.6 ) years and the mean BoNT-A treatment duration was $5.7( \pm 1.2)$ years. All patients complied with the scheduled protocol and showed complete adherence to the PT sessions. At baseline TWSTRS, subscore severity was 14.1 ( \pm 3.1$)$ points and limitations in the patient's range of motion particularly involved lateral flexion and flexion/extension.

In the first phase, in which only BoNT-A treatment was implemented, patients benefited significantly only for the TWSTRS severity $(1.44 \pm 1.30 ; \mathrm{p}:<0.000)$ and TWSTRS total score $(3.01 \pm$ 2.93; $\mathrm{p}:<0.000)$ after 6 weeks (T1). At T2, there were no significant changes in all values compared to baseline.

In the second phase, (BoNT-A+PT) patients already showed significant improvements after 6 weeks (T3). At this point, patients profited significantly with respect to ROM (in degrees) in all 3 movement planes in relation to T2 (increase in flexion/extension: 12.39 ( \pm 12.03 ; $\mathrm{p}:<0.000)$, increase in rotation: 15.72 ( \pm 15.58 ; $\mathrm{p}: 0.001)$, increase in lateral flexion: 8.00 ( \pm 9.65 ; $\mathrm{p}$ : 0.003$)$ ). The SF-36 score at $\mathrm{T} 3$ also improved in terms of the mean of all participants compared to T2. A significant enhancement in the mental health score
(MCS) 4.25 ( \pm 5.44 ; p: 0.004) was seen, but there was no significant progression in the physical health score (PCS) 3.41 ( \pm 5.45 ; p: $0.170)$. Furthermore, all 3 TWSTRS subscales improved significantly from T2 to T3 (improvement in severity: $4.50( \pm 2.12$; $\mathrm{p}:<0.000$ ), improvement in disability: 1.39 ( \pm 1.04 ; p: 0.001$)$, improvement in pain: $3.35( \pm 2.39$; $\mathrm{p}:<0.000)$, increase in total score: 9.24 ( \pm 4.39; $\mathrm{p}:<0.000)$ ). By comparing T3 vs. T4 after another 6 weeks of PT and BoNT-A effects, the participants showed stable measurement values with no significant changes, except in the TWSTRS subscore severity with a significant decrease of 1.17 ( \pm 1.89 ; $p$ : 0.021 ) points.

- Table 1, depicts the comparison of changes in the first phase with changes over the second phase (T0-T2 vs. T2-T4). There were significant improvements in the SF-36 mental health score and no significant improvements in physical health. In the ROM domain, there were significant improvements in 2 out of 3 movement planes (rotation and flexion/extension; p: 0.014 and p: 0.004 respectively), and a tendency of improvement in lateral flexion (p: 0.07). Furthermore, the TWSTRS analysis also showed significant improvements in all 3 subscores. Here, the subscore pain is particularly noteworthy with an improvement of 4.39 points $( \pm 4.07 ; p:<0.000)$ between the 2 study phases. The surface EMG values showed no significant changes.

\section{Discussion}

Our study shows the adjuvant effect of a multimodal physiotherapy program for patients with CD regularly treated with BoNT-A. So far, there have only been a low number of studies and small intervention groups on this subject.

This trial showed that there were significant improvements in mental health (SF-36), in the rotation and flexion/extension dimension of the cervical spine ROM and in every TWSTRS subscore following PT intervention consisting of 2 PT sessions per week over a period of 12 weeks. These results partially conform to outcomes

- Table 1 Results - value changes in the first period vs. value changes in the second period (TWSTRS: Toronto Western Spasmodic Rating Scale, Max. Score: Severity: 35, Disability: 30, Pain: 20; ROM: range of motion, Standard: Flexion/Extension: 110-180, Rotation: 100-170, Lateral flexion: 80-120; Cl: confidence interval; SD: standard deviation; Diff.: difference; scm: sternocleidomastoid)

\begin{tabular}{|c|c|c|c|c|c|}
\hline & $T_{0}-T_{2}($ mean $\pm S D)$ & $\mathrm{T}_{2}-\mathrm{T}_{4}($ mean $\pm \mathrm{SD})$ & Diff. (mean \pm SD) & $\begin{array}{l}\text { Diff. } \mathrm{T}_{0-2}-\mathrm{T}_{2-4} \mathrm{Cl} \\
95 \%\end{array}$ & $\mathbf{p}$ \\
\hline Physical health (SF-36) & $-0.78 \pm 5.30$ & $-3.67 \pm 5.57$ & $2.90 \pm 9.81$ & {$[-7.78 ; 1.98]$} & 0.228 \\
\hline Mental health (SF-36) & $1.29 \pm 4.85$ & $-4.63 \pm 5.38$ & $5.93 \pm 7.46$ & {$[-9.64 ;-2.22]$} & 0.004 \\
\hline Flexion/Extension (ROM) & $0.61 \pm 13.53$ & $-15.73 \pm 15.20$ & $16.33 \pm 25.37$ & {$[-28.95 ;-3.72]$} & 0.014 \\
\hline Rotation (ROM) & $1.00 \pm 14.35$ & $-18.06 \pm 14.69$ & $19.06 \pm 24.58$ & {$[-31.28 ;-6.83]$} & 0.004 \\
\hline Lateral flexion (ROM) & $-3.17 \pm 7.74$ & $-11.22 \pm 13.52$ & $8.06 \pm 17.39$ & {$[-16.70 ; 0.59]$} & 0.066 \\
\hline Severity (TWSTRS) & $-0.50 \pm 1.98$ & $3.33 \pm 1.61$ & $-3.83 \pm 3.01$ & {$[2.33 ; 5.33]$} & 0.001 \\
\hline Disability (TWSTRS) & $-0.22 \pm 0.94$ & $1.50 \pm 1.72$ & $-1.72 \pm 1.96$ & {$[0.74 ; 2.70]$} & 0.003 \\
\hline Pain (TWSTRS) & $-0.56 \pm 2.46$ & $3.83 \pm 2.52$ & $-4.39 \pm 4.07$ & {$[2.36 ; 6.42]$} & $<0.000$ \\
\hline Total Score (TWSTRS) & $-1.28 \pm 3.89$ & $8.67 \pm 4.61$ & $-9.94 \pm 6.99$ & {$[6.47 ; 13.42]$} & $<0.000$ \\
\hline EMG side difference scm muscle (in \%) & $12.82 \pm 28.91$ & $-9.58 \pm 39.37$ & $22.40 \pm 56.88$ & {$[-50.67 ; 5.89]$} & 0.113 \\
\hline EMG side difference trapezius muscle (in \%) & $11.31 \pm 35.63$ & $-1.93 \pm 23.48$ & $13.23 \pm 52.75$ & {$[-39.47 ; 13.00]$} & 0.302 \\
\hline
\end{tabular}


from past studies with a comparable number of examined patients [16-19]. Past studies evaluated from 6 up to 40 patients and was average rated with a moderate quality [7]. Notable in our study there is a significant, considerably improvement in the ROM, which was detected employing ultrasonic-based measurement system (Zebris, > Fig. 2) [9] compared to other studies using only inspection or goniometer for ROM evaluation [16-19]. Using surface EMG we could not show significant changes which maybe related to the known vulnerability to artifacts of EMG [20] and the measurement of standardized muscles (i. e, sternocleidomastoid muscle, trapezius muscle) rather than of individually clinically involved muscles.

Previous trials showed mostly just a trend towards a benefit of the physiotherapy program in the TWSTRS subscores, the SF-36 score, and rotation deviation [16-19]. However, in the above mentioned studies, physical therapy intervention periods were short lasting, i. e, 2 weeks [16] or 4 weeks [18], and involved as many as 5 sessions per week. Moreover, in one of the studies, the BoNT-A injection was not given to all patients which makes it challenging to evaluate potential additional effects of physiotherapy [17].

We designed the PT program to be more practical with respect to the frequency of interventions and duration of treatment involving two 45 min-sessions per week over 3 months [8]. We also used established PT techniques that could be adapted by each physiotherapist to the individual patient's disease profile. This makes our program more convenient and practicable for the "normal" PT treatment setting.

To recapitulate, multimodal physiotherapy is a feasible and well tolerated additional treatment option for patients with cervical dystonia. Patients benefited from the physiotherapy sessions especially with improved range of motion, and reduced pain and severity of symptoms.

\section{Ethical Compliance Statement}

There are no ethical or work ethical objections to this project (IRB processing number: 4122-06/14).

We confirm that we have read the Journal's position on issues involved in ethical publication and affirm that this work is consistent with those guidelines.

\section{Acknowledgements}

The authors thank Nasim Kroegel for language editing and Dr. Thomas Lehmann for statistical analysis support.

\section{Conflict of Interest}

Scholarship for the study duration for one student by IPSEN Pharma.
[1] Steeves TD et al. The prevalence of primary dystonia: a systematic review and meta-analysis. Mov Disord 2012; 27: 1789-9176

[2] Albanese A et al. EFNS guidelines on diagnosis and treatment of primary dystonias. Eur ] Neurol 2011; 18: p. 5-18

[3] Colosimo C, Berardelli A. Clinical phenomenology of dystonia. Int Rev Neurobiol 2011; 98: 509-524

[4] Chan J, Brin MF, Fahn S. Idiopathic cervical dystonia: clinical characteristics. Mov Disord 1991; 6: 119-126

[5] Costa J et al. Botulinum toxin type A therapy for cervical dystonia. Cochrane Database Syst Rev 2005; CD003633

[6] Volkmann J, Dystonie Leitlinie, in Leitlinien für Diagnostik und Therapie in der Neurologie H-C Diener et al., (Hrsg.). Editors. 2012 Thieme Verlag; Stuttgart:

[7] De Pauw J et al. The effectiveness of physiotherapy for cervical dystonia: a systematic literature review. J Neurol 2014; 261: p. 1857-1865

[8] Werner C et al. Multimodal Physiotherapy as an Add-On Treatment to Botulinum Neurotoxin A-Therapy in Patients with Cervical Dystonia. Phys Med Rehab Kuror 2015; 25: 148-152

[9] Dvir Z, Prushansky T. Reproducibility and instrument validity of a new ultrasonography-based system for measuring cervical spine kinematics. Clinical Biomechanics 2000; 15: 658-664

[10] Bullinger M, Kirchberger I, Ware J. Der deutsche SF-36 Health Survey. Übersetzung und psychometrische Testung eines krankheitsübergreifenden Instruments zur Erfassung der gesundheitsbezogenen Lebensqualität. Zeitschrift für Gesundheitswissenschaften 1995; 3: 21-36

[11] Consky E, Lang A, Clinical assessments of patients with cervical dystonia, in Therapy with Botulinum Toxin HM, Jankovic J. (eds). Editor.1994: Marcel Dekker; New York: 211-237

[12] Albanese A et al. Dystonia rating scales: critique and recommendations. Mov Disord 2013; 28: p. 874-883

[13] Reichel G, Stenner A, Jahn A. The phenomenology of cervical dystonia. Fortschr Neurol Psychiatr 2009; 77: 272-277

[14] Loudovici-Krug D. The Influence of Periphere Decontraction on Physiological Parameters of the Cervical Spine Using the Example of the Decontraction According to the Brügger-Concept. Phys Med Rehab Kuror 2014; 24: 191-200

[15] Hülse M, Losert-Bruggner B, Kuksen J. Schwindel und Kiefergelenkprobleme nach Halswirbelsäulentrauma. Man Med Osteopath Med 2001; 39: 20-24

[16] Tassorelli $C$ et al. Botulinum toxin and neuromotor rehabilitation: An integrated approach to idiopathic cervical dystonia. Mov Disord 2006; 21: 2240-2243

[17] Boyce M] et al. Active exercise for individuals with cervical dystonia: a pilot randomized controlled trial. Clin Rehabil 2013; 27: 226-235

[18] Queiroz MA et al. Physical therapy program for cervical dystonia: a study of 20 cases. Funct Neurol 2012; 27: 187-192

[19] El-Bahrawy MN, El-Tamawy MS, Shalaby NM et al. Cervical Dystonia: abnormal head posture and its relation to hand function. Egypt J Neurol Psychiatry Neurosurg 2009; 46: 203-208

[20] Nijmeijer SWR et al. Spectral EMG changes in cervical dystonia patients and the influence of Botulinum Toxin treatment. Toxins 2017; E256: 1-17 